\title{
O SUPREMO TRIBUNAL FEDERAL ENTRE O DIREITO E A TECNOCRACIA CIENTÍFICA: O CASO DO AMIANTO
}

\author{
THE SUPREME COURT BETWEEN LAW AND SCIENTIFIC TECHNOCRACY: THE \\ ASBESTOS CASE
}

\section{Roberta Camineiro Baggio}

Doutora em Direito pela UFSC e Professora Associada da Faculdade de Direito da UFRGS.

E-mail: robertabaggio@uol.com.br

\section{Maristela Medina Faria}

Mestre em Direito pela UFU, professora do Curso de Direito da UniCerrado e advogada.

E-mail: mmedinafaria@gmail.com

Recebido em: $16 / 05 / 2018$

Aprovado em: 16/02/2019

RESUMO: O artigo discute o problema do aumento da utilização de fundamentos científicos em detrimento dos jurídicos nas decisões do Supremo Tribunal Federal (STF) como uma prática própria dos modelos tecnocráticos. Para tanto, analisa um complexo conflito de competência constitucional sobre a regulamentação da utilização do amianto dentro da estrutura federativa brasileira que permite a identificação dos limites e riscos dessa nova postura cada vez mais comum nos tribunais brasileiros. Trata-se do caso do amianto, um conflito que envolve a Lei federal 9.095/95, que regulamenta a questão do uso do amianto no Brasil e Leis estaduais que passaram a proibir o uso do mineral. A análise será feita a partir da $\operatorname{ADI} n^{\circ} 3937$, que demorou dez anos para ser decidida pelo STF.

Palavras-chave: Tecnocracia científica - Conflito federativo - Caso do amianto

\begin{abstract}
The article discusses the problem of increasing the use of scientific grounds to the detriment of the legal ones in the decisions of the Federal Supreme Court (STF) as a practice of the technocratic models. In order to do so, it analyzes a complex conflict of constitutional jurisdiction over the regulation of the use of asbestos within the Brazilian federal structure that allows the identification of the limits and risks of this new posture increasingly common in Brazilian courts. This is the case of asbestos, a conflict involving Federal Law 9.095/95, which regulates the issue of the use of asbestos in Brazil and state laws that have prohibited the use of the mineral. The analysis will be made from ADI $n^{\circ} 3937$, which took ten years to be decided by the STF.
\end{abstract}

Keywords: Scientific technocracy - Federal conflict - Asbestos case 
SUMÁRIO: Introdução ; 1 O STF no contexto do processo de empoderamento tecnocrático das Cortes: a complexidade social e a decadência da política; 2 A questão do amianto no Brasil e o contexto de julgamento da ADI 3937/SP; 3 O conflito federativo no caso do amianto e o esquecimento da dimensão jurídico-normativa: análise dos argumentos dos ministros. Considerações finais.

\section{INTRODUÇÃO}

Diante do complexo quadro de decadência da política e ascensão das instâncias jurisdicionais como um espaço cada vez mais protagonista para a resolução dos conflitos político-sociais, o presente artigo propõe uma reflexão acerca das consequências da adoção de decisões jurídicas com embasamentotécnico-científico que colocam o campo do direito e sua própria normatividade em segundo plano.O processo de tecnocratização dos modos de governabilidade regionais e globais contribuiu para esvaziar os debates acerca da legitimidade em se projetar decisões finais como indubitavelmente corretas e não necessariamente legítimas pela assunção de dispositivos técnicos compreendidos sempre como neutros e, portanto, indisponíveis aos processos de deliberação.

No caso do empoderamento dos poderes judiciários comoloci especializados na técnica de aplicar o direito, o debate acerca da legitimidade encontra-se muito mais concentrado nos modos de aplicar e interpretar as normas jurídicas ou, ainda, na forma de composição das Cortes do que propriamente as fontes do embasamento jurídico da decisão final, já que esse, diferente da produção de normas técnicas por órgãos especializados e distantes do processo formal de deliberação política, encontraalgum cerne de legitimidade resguardado pelo processo legislativopresente nas democracias representativas.Mas, como lidar com a situação cada vez mais corriqueira de normas técnicas não submetidas a qualquer processo de decidibilidadeou, ainda, dados científicos que concorrem com a aplicação das normas jurídicas? Como não pensarna legitimidade que envolve decisões que abarcam, em suas questões de fundo, mais debates científicos do que debates jurídicos ignorando questões normativas básicas?

Essas são algumas das questões a serem refletidas nesse artigo a partir da apreciação pelo Supremo Tribunal Federal (STF) da medida cautelar na ADI n ${ }^{\circ}$ 3937/SP e sua decisão final em agosto de 2017, representativa do que chamamos nesse artigo de "caso do amianto" no Brasil, ou seja, um minério utilizado em artefatos da construção civil que se tornou objeto de diversas legislações regionais a despeito da já existente regulamentação federal e que, por isso, gerou verdadeira controvérsia federativa desencadeada por diversas ADI's no STF que só foram resolvidas depois de dez anos.

O cenário do caso analisado é o complexo modelo federativo consagrado na Constituição Federal de 1988 representado, sobretudo, pela forma de divisão de competências materiais e legislativas. Manteve a estrutura original do modelo norte-americano contemplando competências exclusivas, privativas e residuais ao lado de um modelo cooperativo de federação com a adoção de competências compartilhadas. A funcionalidade e a articulação dessa nova estrutura federativa nunca foram enfrentadas pelo STF. Os modelos adotados não são excludentes, mas como harmonizá-los nas situações em que o debate sobre a quem pertence uma competência possui mais de uma resposta? Casos complexos, como o do amianto, que perpassam os dois modos de distribuição das competências constitucionais seriam ótimas oportunidades de avançar na definição das estratégias e critérios a serem priorizados em situações em que a União aparece ao mesmo tempo como protagonista de competências exclusivas e privativas e também compartilhando outras tantas com os demais entes federados.Ocorre que esse debate tornou-se secundarizado e, em alguns momentos, até mesmo invisibilizado diante dos dados científicos 
apresentados ao longo do processo de julgamento, o que gerou consequências complicadas no cotidiano de todas as estruturas da vida social em que a questão tinha alguma incidência.

Sendo fruto de uma pesquisa bibliográfica e documental, foram utilizadas as decisões do STF sobre o caso em questão como fontes primárias e,como fontes secundárias, livros e artigos relacionados ao tema. A estrutura do artigo está dividida em três partes. A primeira desenvolve de forma breve o contexto de ascensão da tecnocracia e como ele atinge as Cortes, na segunda é apresentada a complexidade da questão do amianto no Brasil e como se desenvolveram as principais controvérsias jurídicas sobre o tema e, por fim, a terceira, em que as decisões são analisadas apresentando a secundarização dos conflitos federativos diante da questão científica e algumas de suas consequências.

\section{O STF NO CONTEXTO DO PROCESSO DE EMPODERAMENTO TECNOCRÁTICO DAS CORTES: A COMPLEXIDADE SOCIAL E A DECADÊNCIA DA POLÍTICA}

A ideia de tecnocraciapode ser compreendida como um fenômeno originário das sociedades industriais, consolidada como um modelo inexorável aos processos de busca de níveis elevados de eficiência e padronização do desenvolvimento industrial, que não se limitou no tempo e no espaço a uma determinada etapa inicial desse processo. A tecnocraciafaz "[...]referência a um sistema social que não apenas superou a revolução da máquina, mas enfrentou a segunda revolução industrial, que é a organização" (BOBBIO, 1998, 59, p. 1244)e que, segundo Bobbio, alcançou a terceira revolução industrial (designada pela automação/computador), desencadeando o surgimento de novos tipos de tecnocracia (BOBBIO, 1998, 59, p. 1244).

Jürgen Habermas, quando do debate sobre técnica e ciência, interpretou tal fenômeno a partir de um horizonte teórico weberiano concebendo-o como uma nova etapa da dominação burocrática, que já não seria mais racionalizada apenas pelos critérios da divisão do trabalho, mas por competências estruturadas pelo advento das novas tecnologias (HABERMAS, 1993, p.107). No sistema de desenvolvimento capitalista-industrial, o fenômeno da tecnocracia perderia a qualidade de simples fato ou evento para estabelecer-se como um modelo que torna inevitável uma nova dinâmica na seara da própria política, dissolvendo o problema da decisão e tornando-a dependente do rol de técnicas eficientes disponíveis. Tais considerações levaram Habermas a afirmar que "[...] a atividade decisória que resta efetivamente ao político no Estado técnico é apenas fictícia" (HABERMAS, 1993, p. 107), uma vez que as supostas saídas para as questões políticas passam a estar atreladas ao domínio das soluções técnicas. E é exatamente a nova dinâmica de dominação imposta pelo modelo tecnocrático - que passou a afetar não só os processos produtivos, mas diretamente a esfera da política -conduzindoalguns estudiosos da temática às leituras vinculativas da tecnocracia à ideia de uma ideologia.

Hans Lenk, por exemplo, em um sentido muito próximo ao raciocínio de Habermas, parte de uma definição de tecnocracia pressupondo-a como "[...] toda dominação com o auxílio da técnica e para toda preferência de decisões sob critérios da praticabilidade e da eficiência técnicoadministrativa. Nisso estão incluídas valorações sociais inconscientes manipulativas, em parte deliberações incorporadas" (LENK, 1975, p. 129). Do mesmo modo, Bobbio também apresenta quais seriam os princípios fundamentais da ideologia tecnocrática em seu entendimento:

[...] além da predominância da eficiência e da competência, a concepção da política como reino da incompetência, da corrupção e do particularismo, o tema do desinteresse das massas a respeito da res publica com a consequente profissionalização do decision-making, a tese do declínio das ideologias 
políticas e a substituição de uma espécie de koiné tecnológica. (BOBBIO, 1998, p. 1245)

A presença cada vez mais crescente de órgãos técnicos que ganharam espaço de decidibilidade sobre questões políticas relevantes passa a ser uma realidade dentro das estruturas dos Estados ocidentais, sobretudo, depois da Segunda Guerra Mundial. O ápice desse processo ocorre com a crise do Estado Social quando a busca por mais eficiência estatal gera um deslocamento de poder das instâncias de deliberação política para os órgãos técnicos, capazes de supostamente gerar soluções derivadas de uma expertise que está posta como neutra diante da complexidade dos desafios colocados à sociedade ao mesmo tempo em que, como ressaltou Bobbio na passagem anterior, a política é cada vez mais vista como o "reino da incompetência". Contudo, como ressalta Benoit Frydman no importante debate sobre o fim do Estado de Direito, as normas técnicas assim como as normas jurídicas são "meios de dirigir os homens e os comportamentos", o que desmascara o discurso de neutralidade da técnica, afinal, sempre serão necessárias decisões acerca desses comportamentos, ou melhor, de quais são os comportamentos desejados e convenientes ao grupo estrito de pessoas que podem tomar as decisões sobre a produção da tecnicidade. E, nesse sentido, a tecnocracia cumpre "[...] uma função essencialmente ideológica, que consiste em mascarar a natureza política das escolhas da qual procedem as normas e os efeitos que elas produzem" (FRYDMAN, 2016, p. 82)

Note-se que, em síntese, estão entre as estratégias que se estabelecem em torno do modelo tecnocrático a utilização dos conhecimentos científicos e técnicos como necessidades inexoráveis às resoluções das complexidades sociais, bem como a inevitabilidade fática da decadência da política, quese torna não mais tão interessante para a sociedade, já que boa parte dos indivíduos passa a considerá-la como um símbolo da incompetência, abandono do interesse comum e o espaço da corrupção. Bobbio, então, afirma que o regime tecnocrático se resume, em um sentido mais estrito, como sendo aquele em que o agente tecnocrata direciona, fundamentado em regras da competência, os meios da ação social, bem como os seus fins (BOBBIO, 1998, p. 1246), de modo a converter-se em uma elite técnico-científica que também facilmente pode transformar-se em uma elite de poder na sociedade (MARTINS, 1970, p. 41).

A credibilidade do espaço da política é substituída paulatinamente pela inevitabilidade demonstrada pelos resultados científicos e estudos técnicos que passam a ser determinantes para as decisões adotadas, contribuindo, inclusive para a neutralização das responsabilidades políticas. Alessandro Pinzani, ao desenvolver as premissas do discurso tecnocrático, destaca justamente a despersonalização da política, já que as decisões são tomadas como medidas necessárias, derivadas de inevitáveis estudos técnicos, ou seja, uma mera "consequência lógica da aplicação prática de tal saber" (PINZANI, 2013, p. 160). Dentro desse horizonte conjuntural, os espaços de decidibilidade política não só perdem sua força legitimadora a priori, como também se estabelece uma zona de conforto aos atores políticos que deixam de sentir-se diretamente responsáveis pelas decisões, já que o seu fundamento está sempre vinculado a um estudo técnico-científico, supostamente desinteressado e neutralizado em relação ao campo da política.

Ao lado das estruturas executivas do Estado, os órgãos que aplicam o direito como os poderes judiciários, não tardaram a ganhar destaque nessa conjuntura de crise do Estado Social e de valorização tecnocrática, quer seja pelo crescimento de seu papel técnico potencializadopor um Estado altamente produtor de normas, quer seja, pelo aumento das demandas judicializáveisque, como consequência do primeiro fator, também ganhou força diante dasdificuldades do poder executivo em responder às promessas do Estado Social.

A expansão da utilização das normas técnicas em detrimento das normas jurídicas, nesse contexto, ocorreu de um modo relativamente tranquilo no âmbito dos poderes judiciários, uma vez que aquelas sempre foram aplicadas de forma subsidiária a estas, o que, segundo Benoit Frydman causou certa indiferença por parte dos atores envolvidos quando do aumento da 
utilização de parâmetros técnicos e científicos que passaram a uma situação de concorrência com as normas jurídicas. A indagação do autor diante desse quadro é:

Podemos, entretanto, nos perguntar se esta posição deve ser mantida enquanto, as normas técnicas e os indicadores de governança concorrem com as regras jurídicas, substituindo-se a elas em domínios cada vez mais amplos e importantes, e até "pilotam" as regras de direito e as instituições políticas e judiciárias. (FRYDMAN, 2016, p. 87)

No caso brasileiro, ainda que não tenhamos tido um Estado Social como nos países do norte, o empoderamento de nosso poder judiciário se deu, sobretudo, no processo de redemocratização. Passados mais de vinte anos do regime ditatorial o resultado da constituintedesvela um texto com uma nítida contemplação de mecanismos de empoderamento das estruturas disponíveis e um aceleramento dos processos de judicialização. Por um lado, o rol de direitos estabelecido do modo mais completo já visto em nossa história e, por outro, o reforço a instituições como o Ministério Público e as Defensorias Públicas aptas a efetivar direitos não realizados, assim como uma maior amplitude para a atuação do Supremo Tribunal Federal (STF) com o aumento dos legitimados ativos para propor Ações Diretas de Inconstitucionalidade, bem como pela previsão da Arguição de Descumprimento de Preceito Fundamental (ADPF). Regulamentando tais dispositivos há as Leis federais $n^{\circ}$ 9.868/99 e $n^{\circ}$ 9.882/99 que ampliaram os parâmetros e os objetos de controle de constitucionalidade no ordenamento brasileiro. A conclusão é a de que, ainda que por motivos históricos diferentes, "[...]os mecanismos jurídicos que se procurou inserir na Constituição Federal de 05.10.1988 alcançam o mesmo movimento concentrador de poder tecnocrático já observado em outros países ocidentais no $2^{\circ}$ pós-guerra" (PÁDUA, 2008, p. 139).

Com esta nova conjuntura, propiciada pela Constituição Federal de 1988, muitas decisões políticas e sociais fundamentais para a sociedade brasileira deixaram de ser tomadas pelas tradicionais instituições políticas, poder executivo e poder legislativo, e deslocaram-se para o poder judiciário, mais especificamente para o Supremo Tribunal Federal que caracteriza-se como uma "comunidade restrita de técnicos do direito"1. O controle do poder político-estatal passa, então, a ser exercido de um modo muito mais intenso por juristas representantes de um pequeno grupo de intérpretes que, em tese, dominam cada vez com mais "competência" a intricada técnica do direito (PÁDUA, 2008, p. 47).

O primeiro problema que decorre desse cenário é a questão cada vez mais debatida pelos teóricos sobre a legitimidade desse movimento de deslocamento tecnocrático do processo deliberativo, já que os ministros do STF não passaram por um processo de legitimação política para exercerem de modo tão absoluto a palavra final sobre questões políticas básicas, como se a técnica do direito pudesse suplantar ou substituir o espaço da política. Para Claus Offe, por exemplo, uma das principais críticas aesse modelo tecnocrático é o fato de que este promove um processo de desdemocratização e despolitização, sustentadopela tese de que a tecnocracia é a consequência da "civilização científica" o que, ocasiona inevitavelmente, um "retrocesso e esvaziamento funcional das instituições democráticas" (OFFE, 1975, p. 70-71).

O segundo problema é o foco do presente artigo e relaciona-se com o aumento de demandas complexas permeadas por diversos conhecimentos científicos alheios ao direito e que têm dominado não só o debate de tais demandas no STF como têm servido, não raras vezes, como embasamento prioritário das decisões dos ministros, ocasionando uma secundarização dos argumentos jurídico-normativos. Essa situação gera uma atuação complexa e contraditória, já que oSTF, órgão protagonista do processo de tecnocratização jurídica do país, secundariza esse papel

${ }^{1}$ Este termo é utilizado por João Pedro Chaves Valladares Pádua (2008).

Revista de Direito Brasileira | Florianópolis, SC | v. 23 | n. 9 | p. 112-131 |Mai./Ago. 2019 
para assumir prioritariamenteuma tecnocratização científica distante de sua expertise e competência.

Dessa forma, é possível falar em duas perspectivas tecnocráticasna atuação do STF. Por um lado, este órgão é composto por "técnicos em direito", que passam a decidir questões políticas e sociais fundamentais para a sociedade, que deveriam estar a cargo do Poder Executivo, Poder Legislativo, partidos políticos e sociedade civil, contribuindo sobremodo para o processo de decadência e deslegitimação da política. Por outro, o STF ao decidir casos que, muitas vezes são de alta complexidade e envolvem questões de várias áreas da ciência, baseia suas decisões em estudos científicos e dados técnicos disponíveis, afastando a dimensão jurídico-normativa das situações, dando origem a uma vertente que denominaremos nesse trabalho de tecnocracia científica do STF. Nessa segunda vertente tecnocrática, os técnicos em direito, ou seja, os ministros do STF, embasados por conhecimentos científicos e dados especializados, têm deslocado ou secundarizado os argumentos do campo jurídico-normativo para o campo científico, abrindo mão de suas principais responsabilidades, no mesmo sentido já descrito anteriormente por Pinzani.

A inadequação da priorização dessa dimensão tecnocrática é, sobretudo, a variabilidade e possibilidade de sua instrumentalização em prol de determinadas conveniências, já que "[...] a cada momento vemos os 'especialistas' apontando caminhos 'científicos' e 'técnicos' para serem seguidos por todos" (ROTHEN, 2015, p. 07), o que facilita um processo de condicionamento dos "saberes especializados" a determinados interesses que nem sempre estão claramente colocados na linha de frente das dinâmicas do poder, sobretudo, porque no modelo de um contexto tecnocrático "as negociações políticas são compreendidas como expressão do passado, no qual o interesse particular reina sobre a sociedade" (ROTHEN, 2015, p. 07).

Nesse sentido é pertinente a observação da então ministra Ellen Gracie de que o STF não é uma academia de ciências ${ }^{2}$ e essa tecnocracia exercida pelo tribunal é limitada e inadequada para solução de casos de alta complexidade, típicos de uma sociedade de risco compartilhado ${ }^{3}$. Ademais, se o avanço e os debates da ciência contemporânea são capazes de fornecer um catálogo para toda sorte de soluções que podem ser eleitas de acordo com as conveniências do momento, essa dinâmica ainda ressalta a perversidade da perda de responsabilidade dos agentes públicos diretamente implicados nos processos de decidibilidade, no caso os ministro do STF, já que a aplicação jurídico-normativa do direito, motivo pelo qual foram escolhidos para compor a corte, acaba deixada de lado para a adoção de medidas supostamente inevitáveis de acordo com as demonstrações dos saberes científicos envolvidos na questão.

O caso a ser trabalhado no presente artigo envolve exatamente uma situação complexa em que sobram divergências científicas sobre o tema a serem escolhidas por cada tipo de interesse envolvido. Trata-se do caso do amianto que será abordado aqui, sobretudo, a partir da Ação Direta de Inconstitucionalidade $\mathrm{n}^{\circ} 3937 / \mathrm{SP}$, fonte que sintetiza características de um modelo de tecnocracia científica cada vez mais presente nas decisões do STF.

\section{A QUESTÃO DO AMIANTO NO BRASIL E O CONTEXTO DE JULGAMENTO DA ADI 3937/SP}

Antes de adentrar na discussão judicial sobre a qual versa a Ação Direta de Inconstitucionalidade $\mathrm{n}^{\circ}$ 3937/SP, convêm fazer alguns esclarecimentos sobre a questão do

\footnotetext{
${ }^{2}$ Esta expressão foi utilizada pela ministra em algum de seus votos entre eles o proferido no julgamento da Ação Direta de Inconstitucionalidade $n^{\circ} 3510 / \mathrm{DF}$ e no julgamento do pedido de liminar na ADI $n^{\circ} 3937 / \mathrm{SP}$.

${ }^{3}$ A expressão sociedade de risco foi introduzida e divulgada por Ulrich Beckem 1986. Para o autor a sociedade contemporânea é uma sociedade de risco global, já que seus principais desafios são perigos produzidos pela própria civilização e que não podem ser delimitados socialmente nem no tempo e nem no espaço. (BECK, 2002, p. 29).
}

Revista de Direito Brasileira | Florianópolis, SC | v. 23 | n. 9 | p.112-131 |Mai./Ago. 2019 
amianto, de modo que se possa notar a complexidade não só científica que permeia o tema, mas também econômica e social. $\mathrm{O}$ amianto é um mineral encontrado na natureza e que tem sido constantemente utilizado na indústria durante os últimos anos. Há basicamente dois grupos de amianto: as serpentinas e os anfibólios. O primeiro grupo tem como principal representante a variedade crisotila, também conhecido como "amianto branco", e tem como característica principal, fibras curvas e maleáveis. Já o segundo grupo, qual seja, os anfibólios, são pouco explorados e representam apenas $5 \%$ (cinco por cento) de todo o amianto explorado e consumido mundialmente e é proibida a sua exploração e comercialização em grande parte do planeta, em virtude dos malefícios que causam à saúde do ser humano ${ }^{4}$.

$\mathrm{O}$ amianto branco que é utilizado, principalmente, na construção civil e para o isolamento acústico e térmico, está banido em 58 países $^{5}$, entre eles estão, principalmente, os países europeus e outros países como o Japão, Uruguai e Emirados Árabes. No Brasil, apenas seis Estados ${ }^{6}$ conseguiram efetivar, pelo menos momentaneamente, a proibição para a utilização do amianto branco, são eles: Rio de Janeiro, Rio Grande do Sul, Pernambuco, São Paulo, Amazonas e Mato Grosso. Os Estados do Espírito Santo e do Pará tiveram os projetos de lei que disciplinavam a utilização do amianto branco vetados pelos Governadores dos Estados. Já o Estado do Mato Grosso do Sul teve a Lei estadual $n^{\circ} 2.210 / 01$, que proibia a comercialização de produtos à base de amianto/asbesto destinados à construção civil, declarada inconstitucional em virtude da procedência da Ação Direta de Inconstitucionalidade $n^{\circ}$ 2396/MS. Neste julgamento, o STF entendeu por unanimidade de votos que o Estado do Mato Grosso do Sul teria desrespeitado a competência prevista constitucionalmente, ao elaborar a referida lei. Isso porque, compete à União legislar a partir de normas gerais (art. 24, § $1^{\circ}$ ) sobre produção e consumo (art. 24, V, CF), proteção do meio ambiente e controle da poluição (art. 24, VI, CF), bem como sobre a proteção e defesa da saúde (art. 24, XII, CF).

À exceção do Estado do Mato Grosso e do Amazonas, todos os outros Estados acima mencionados ou tiveram suas leis vetadas pelos Governadores ou essas Leis são objeto de questionamento sobre a constitucionalidade junto ao Supremo Tribunal Federal. Tal conflito ocorre já que as Leis Estaduais editadas, proibindo ou restringindo a utilização do amianto da variedade crisotila, estariam invadindo competência legislativa concorrente da União. Destaca-se que desde 1995 existe uma Lei federal - Lei no 9.055/95 - que disciplina a extração, industrialização, utilização, comercialização e transporte do asbesto/amianto, bem como das fibras naturais e artificiais, de qualquer origem, utilizadas para o mesmo fim. Esta Lei permite no artigo $2^{\circ}$ a extração, utilização, industrialização ou comercialização do amianto da variedade crisotila ${ }^{7}$. Regulamentando esta Lei, há o Decreto n ${ }^{\circ} 2.350$ de 15 de outubro de 1997.

O Brasil possui em atividade apenas uma mina para exploração do amianto branco, que está localizada em Minaçu, no Estado de Goiás, e atualmente está entre os cinco principais produtores, consumidores e exportadores mundiais deste tipo de amianto.

Há grande controvérsia a respeito da utilização do amianto, e elas referem-se, principalmente, aos malefícios que esta substância causa à saúde do homem e ao meio ambiente.

\footnotetext{
4 Todas estas informações foram retiradas do site do Instituto Nacional do Câncer (INCA). Disponível em: http://www1.inca.gov.br/conteudo_view.asp?ID=15. Acesso em: 22 de julho de 2015.

${ }_{6}^{5}$ Disponível em: http://www.abrea.com.br/07panorama.htm. Acesso em: 22 de julho de 2015.

${ }^{6}$ Alguns municípios também possuem leis proibindo ou restringindo a utilização do amianto da variedade crisotila, entre eles: Barretos, Recife e Natal. Conferir: http://www.abrea.com.br/QUADRO\%20ATUAL\%20banimento.htm. Acesso em: 23 de julho de 2015.

${ }^{7}$ Tais conflitos normativos poderão ter um fim, já que a referida Lei federal é objeto da Ação Direta de Inconstitucionalidade $\mathrm{n}^{\circ}$ 4066/DF. Esta ação foi proposta em 2008 pela Associação Nacional dos Procuradores do Trabalho (ANPT) e pela Associação Nacional dos Magistrados da Justiça do Trabalho (ANAMATRA) e questiona a constitucionalidade do artigo $2^{\circ}$ da Lei federal $n^{\circ} 9.055 / 95$ que permite a livre extração, industrialização, exploração e comercialização do asbesto/amianto da variedade crisotila (asbesto branco).
} 
Segundo dados da Organização Internacional do Trabalho (OIT) 100.000 (cem mil) trabalhadores morrem por ano em virtude de doenças causadas pela exposição ao asbesto ${ }^{8}$.

A Ação Direta de Inconstitucionalidade $n^{\circ}$ 3937/SP foi proposta em agosto de 2007, pela Confederação Nacional dos Trabalhadores na Indústria (CNTI), uma entidade sindical de grau superior, alegando a inconstitucionalidade da Lei estadual $n^{\circ}$ 12.684/07 do Estado de São Paulo. Tal Lei proíbe o uso, no Estado de São Paulo de produtos, materiais ou artefatos que contenham quaisquer tipos de amianto ou asbesto ou outros minerais que, tenham fibras da referida substância em sua composição. A ADI 3937/SP foi colocada em pauta para ser julgada junto com a ADI 3357/RS, também proposta pela CNTI, em 2004, questionando a constitucionalidade da Lei estadual $n^{\circ} 11.643 / 01$ do Estado do Rio Grande do Sul, que disciplina a proibição de produção e comercialização de produtos à base de amianto no Estado.

Pois bem, nas ADI's3937/SP e 3357/RS alegou-se a inconstitucionalidade das Leis estaduais $\mathrm{n}^{\circ} 12.684 / 07$ e $\mathrm{n}^{\circ} 11.643 / 01$, respectivamente, tendo em vista que elas proíbem a utilização nos Estados, de produtos, materiais ou artefatos que possuam quaisquer tipos de amianto ou asbesto ou outros minerais que, porventura, contenham fibras de amianto na sua composição; ocasionando um conflito de competência federativa em relação à Lei federal $\mathrm{n}^{\circ}$ 9.055/95, que permite a extração, industrialização, utilização e comercialização do asbesto/amianto da variedade crisotila (asbesto branco).

Em 8 de maio de 2003 o STF teve a oportunidade de manifestar-se, pela primeira vez, sobre leis estaduais que vedavam a utilização e comércio do amianto branco através do julgamento das Ações Diretas de Inconstitucionalidade $n^{\circ}$ 2396/MS, de relatoria da Ministra Ellen Gracie e a de $n^{\circ}$ 2656/SP cujo relator foi o Ministro Maurício Corrêa. Nesta oportunidade, ficou firmado o entendimento no sentido da inconstitucionalidade formal de alguns dos dispositivos das leis estaduais que proibiam a utilização e comércio do amianto, tendo em vista a invasão de competências da União.

Após o julgamento destasADI's, foram propostas outras questionando as leis estaduais que de alguma forma restringissem a exploração do amianto branco. Ocorre que, as que mais ganharam destaque foram as ADI's3937/SP e 3357/RS, sobretudo pela mudança de entendimento que ocasionaram no STF, a partir da adoção de argumentos essencialmente fundamentados em questões científicas. Como será analisado no próximo item, essa guinada interpretativa ocorreu, principalmente, nos debatesdo julgamento da medida cautelar na ADI 3937/SP, por isso a sua escolha como objeto principal de análise desse artigo.

$\mathrm{Na}$ oportunidade, quando do julgamento do pedido de liminar para que fosse suspensa a vigência da Lei estadual questionada na ADI 3937/SP, os ministros Marco Aurélio, Menezes Direito e Ellen Gracie votaram pela concessão da liminar seguindo a até então jurisprudência da Corte; por outro lado, os ministros Ricardo Lewandowski, Eros Grau, Cármem Lúcia, Joaquim Barbosa, Carlos Brito, Celso de Mello e Cezar Peluso pela não concessão. O ministro Gilmar Mendes não participou da sessão de julgamento, portanto não proferiu seu voto. Dessa forma, por 7 (sete) votos contrários e 3 (três) favoráveis, a liminar não foi concedida e a lei continuou vigente. Foi possível perceber que as informações científicas e os dados técnicos disponibilizados foram determinantes nessa mudança de posição da corte, como será analisado adiante.

Decidida a liminar no mesmo mês do protocolo da inicial, o STF demoraria cinco anos para iniciar o julgamento conjunto das ADI'sn ${ }^{\circ}$ 3937/SP e n ${ }^{\circ} 3357 / \mathrm{RS}$. Contudo, logo após o voto do ministro Ayres Britto (relator da ADI n ${ }^{\circ} 3357 / \mathrm{RS}$ ), que decidiu pelaimprocedênciada ação e o voto pela procedência do ministro Marco Aurélio (relator da ADI n³937/SP), o julgamento foi suspenso tendo sido retomado apenas em agosto de 2017, dez anos depois do início do processo. A tendência de reconhecimento da legitimidade das leis estaduais que marcou

$8 \quad$ Conferir $\quad$ Resolução
http://www.ilo.org/public/english/protection/safework/health/resolution_on_asbestos.pdf. Acesso em:

Revista de Direito Brasileira | Florianópolis, SC | v. 23 | n. 9 | p.112-131 |Mai./Ago. 2019 
a decisão da medida cautelar foi mantida na decisão final, sendo visível o avanço e termos de aprofundamento dos argumentos jurídicos sobre as questões federativas. O espectro da cientificidade, contudo, não deixou de rondar a decisão principal, demostrando sua força e os desafios postos ao mundo jurídico.

\section{O CONFLITO FEDERATIVO NO CASO DO AMIANTO E O ESQUECIMENTO DA DIMENSÃO JURÍDICO-NORMATIVA: ANÁLISE DOS ARGUMENTOS DOS MINISTROS}

Em 29 de agosto de 2007deu-se início ao julgamento do pedido de medida cautelar da ADI $n^{\circ} 3937 / \mathrm{SP}$, em que a CNTI alegou, como justificativa principal de sua legitimidade os riscos causados pela Lei paulista $\mathrm{n}^{\circ} 12.684 / 07$ ao aumento do desemprego aos trabalhadores do setor por ela representados. Quanto ao mérito da questão suscitou três ordens de fatores. A primeira, quanto à afronta à "reserva legal proporcional" e à livre iniciativa dispostas nos incs. II e LIV do art. $5^{\circ}$ e no parágrafo único do art. 170 da $\mathrm{CF}$, uma vez que a proibição ao uso do amianto no mercado é desproporcional diante dos índices científicos de tolerância e isenção de malefícios do produto, gerando um impedimento demasiado oneroso ao desenvolvimento de todas as atividades econômicas vinculadas ao produto.

Em segundo lugar, são alegados os vícios de inconstitucionalidade, que estariam divididos em duas partes: o de inciativa, já que supostamente a proposição da referida Lei estadual seria competência privativa do poder executivo, de acordo com os incs. II e IV do art. 84 da CF e não do poder legislativo, como acabou ocorrendo no presente caso. $\mathrm{O}$ segundo guarda o cerne da controvérsia jurídica que envolve a questão do amianto no Brasil e é o da usurpação das competências de legislar da União, seja de forma privativa (incs. I, XI e XII do art. 22), seja de forma geral, quanto à competência concorrente estabelecida no $\S 1^{\circ}$ do art. 24 , sobretudo, no presente caso, no que diz respeito às matérias elencadas nosincs. V, VI e XII do mesmo artigo.

A alegação foi a de que, diante da existência da Lei federal 9.095/95 a União estabeleceu seu papel constitucional de regulamentar a matéria tanto privativamente, no que tange à regulamentação do comércio, transporte e recursos minerais (incs. I, XI e XII do art. 22), assim como de modo concorrente, estabelecendo normas gerais ( $\$ 1^{\circ}$ do art. 24) de produção e consumo; proteção do meio ambiente e controle da poluição; e proteção e defesa da saúde (incs. V, VI e XII do art. 24). Ou seja, a Lei federal 9.095/95 atenderia ao mesmo tempo as prerrogativas privativas da União, postas no art. 22, e também cumpriria o papel de norma geral, estabelecido no $\S 1^{\circ}$ do art. 24 do rol de competências concorrentes entre os entes da federação. $\mathrm{Na}$ medida em que os Estados-membros começaram a legislar no âmbito regional acerca do uso do amianto, de modo mais restritivo do que o disposto na Lei federal 9.095/95, teriam ocasionado uma insuperável invasão das competências constitucionais da esfera federal que afronta o princípio federativo consagrado no art. $1^{\circ}$ e no inc. I do $\S 4^{\circ}$ do art. 60 do texto constitucional.

Por fim, a terceira ordem de alegações diz respeito à afronta à autoridade do STF, uma vez que a lei paulista repete conteúdo de outra Lei (10.813/01), produzida no próprio Estado de São Paulo e já declarada inconstitucional no julgamento da ADI n 2656/SP, julgada em 2003.

No voto do relator, o ministro Marco Aurélio, de modo muito sucinto e objetivo, defere o pedido de medida cautelar optando, assim, pela suspensão da Lei estadual $n^{\circ} 12.684 / 07$ até a decisão final da ADI, sob o argumento de que a referida Lei causaria embaraços à comercialização dos produtos que contém amianto, o que acabaria gerando consequências ao comércio interestadual, matéria de competência da União, de acordo com o inc. VIII do art. 22 da $\mathrm{CF}$, tal qual já debatido e enfrentado na ADI n 2656-9/SP.

Na sequência dos debates pronunciou-se o ministro Eros Roberto Grau, decidindo pelo indeferimento do pedido de liminar sob o argumento de que a questão era demasiada complexa 
para ser esgotada diante da alegação de quebra do princípio da livre iniciativa e que "[...] a matéria não pode ser examinada única e exclusivamente desde a perspectiva formal" (BRASIL, 2008, p. 74), já que, a verdadeira inconstitucionalidade estava na Lei federal que não cumpria um papel adequado de cuidar da saúde da população afrontando o art. 196 da CF.

Os debates que se seguiram foram no sentido, primeiro, da Corte se defrontar com uma série de laudos científicos controvertidos sobre uma matéria complexa e sustentada por interesses econômicos de grande monta. Nesse sentido, se pronunciaram os ministros Gilmar Mendes e Ellen Gracie. Em segundo lugar, sobre a complexidade federativa de matérias tão amplas como direito à saúde gerarem, na dinâmica federativa das competências compartilhadas, um acúmulo de regulamentações diferentes sobre o mesmo tema. Acompanharam ainda, o relator, a ministra Carmem Lúcia e o ministro Ricardo Lewandowski e, por fim, o ministro Joaquim Barbosa pediu vistas do processo.

O julgamento foi retomado em 04 de junho de 2008 e, antes da apresentação do voto vista do ministro Joaquim Barbosa, o ministro relator, Marco Aurélio, reforçou seus argumentos discorrendo sobre os efeitos práticos da proibição do uso do amianto no Estado de São Paulo, sendo o principal deles, a derrogação da Lei federal no território paulista. Tal derrogação, na opinião do ministro, seria inaceitável, sobretudo, sob o ponto de vista da dinâmica federativa. Para o ministro, se os Estados-membros decidissem começar a proibir a comercialização de produtos cancerígenos, como seria o caso do tabaco, haveria um inevitável esvaziamento da competência federativa privativa da União de legislar sobre a organização do comércio. Por isso, reiterou o ministro sua posição inicial sustentando que, nesse caso há uma "situação concreta em que o vício articulado é o formal e que não poderia, como quer o Estado de São Paulo, restringir no cenário jurídico a aplicação da Lei federal, proibindo a comercialização do amianto no respectivo âmbito". (BRASIL, 2008, p. 36)

No voto vista, o ministro Joaquim Barbosa iniciou sua estratégia argumentativa com um panorama sobre o cenário dos pedidos de inconstitucionalidade a leis estaduais semelhantes à Lei paulistae ao histórico dos julgamentos já efetuados no STF sobre a temática no ano de 2003. A partir desse ponto, sistematizou quatro conclusões às quais o Tribunal chegou. As duas primeiras, vinculadas à $\mathrm{ADI} \mathrm{n}^{\circ}$ 2396/MT, diriam respeito à decisão da Corte de "se afastar da questão técnica relativa aos efeitos danosos do amianto crisotila" (BRASIL, 2008, p. 39) e, depois de que a Lei federal $n^{\circ}$ 9.055/95 seria "lei geral que afastaria a lei estadual" (BRASIL, 2008, p. 39).

As outras duas conclusões, ligadas ao julgamento da ADI n ${ }^{\circ}$ 2656/SP, diriam respeito a um debate federativo mais stricto sensu. Primeiro, "que o amianto faria parte do rol de competências exclusivas da União" (BRASIL, 2008, p. 39); depois "a ausência de qualquer interesse local a fundamentar a legislação estadual” (BRASIL, 2008, p. 39).

Nenhuma dessas conclusões continuariam sendo corretas na visão do ministro, por isso o pedido de vistas. Antes, contudo, de expor sua compreensão sobre a matéria, fez no voto"alguns esclarecimentos de natureza científica" (BRASIL, 2008, p. 39), discorrendo por cerca de três páginas sobre os malefícios do amianto crisotila com base em estudos científicos. Esses esclarecimentos tornaram-se essenciais para o entendimento da mudança de posição da Corte sobre o tema porque passaram a protagonizar o debate, colocando em segundo plano os demais aspectos da questão federativa, como será visto mais adiante. Isso ocorreu não só no voto vista do ministro, mas também na revisão de alguns dos votos que já haviam sido proferidos e nos votos que ainda não haviam sido prolatados.

Ainda no voto vista, logo após a exposição dos argumentos científicos, o ministro Joaquim Barbosa afirmou o alto nível de exigência da jurisprudência da Corte quanto às limitações estaduais em relação à livre circulação, que colocariam as decisões do STF fora de padrões de razoabilidade. Seguiu-se, então, uma série de citações jurisprudenciais anteriores ao texto constitucional de 1988 em que os dilemas federativos da Corte estavam ligados ao debate da divisão clássica de competências exclusivas da União e o poder de legislar residual dos 
Estados em relação a matérias consagradas como próprias da esfera federal. Isso porque a ideia de uma divisão de competências compartilhadas é uma inovação da carta constitucional de 1988. Seria, portanto, impossível, que os debates jurisprudenciais enfrentassem o tema sobre os limites do poder compartilhado de legislar de cada esfera da federação, já que esse modelo de divisão de competências não estava dado antes de 1988.

Ocorre que,o ministro demonstrou essa compreensão sobre a transformação do modelo federativo de 1988, mas passou a concentrar-se apenas nessas inovações constitucionais sem qualquer menção aos temas de exclusividade da União para legislar que também circundam a questão do amianto no Brasil e que permaneceram no texto da CF de 1988 - como a questão dos recursos minerais, o transporte e o comércio - para se fixar nas questões compartilhadas de proteção à saúde e meio ambiente que, diante do debate científico,converteram-senas únicas a serem tratadas sobre a matéria.

O ministro afirmouem seu voto estar convencido de que as normas estaduais que regulamentam a questão do amianto e que estão sendo questionadas no STF não são inconstitucionais por duas razões. A primeira, ligada à existência da Convenção $\mathrm{n}^{\circ} 162$ da OIT, ratificada pelo Brasil e que prevê a adoção de legislação protetiva dos trabalhadores expostos ao amianto. Nesse sentido, os Estados-membros estariam cumprindo esse compromisso internacional muito mais do que a União, sobretudo, porque o item 2 do art. $3^{\circ}$ da referida Convenção prevê que a legislação nacional, adotada com o intuito de prevenir e controlar os riscos da exposição ao amianto "[...] deverá ser submetida a revisão periódica, à luz do desenvolvimento técnico e do aumento do conhecimento científico", o que não estaria sendo feito no âmbito federal, mas estadual com a criação de novas legislações mais protetivas dos trabalhadores do que a federal.

Quanto à segunda razão pela qual o ministro acreditava na constitucionalidade das leis estaduais é que a Convenção 162 da OIT, uma vez ratificada pelo Brasil, é que teria traços verdadeiros de lei geral e não mais a Lei federal. Desse modo, perderia o sentido o debate entre lei geral e lei específica, já que, nas palavras do próprio ministro:

A distinção entre lei geral e lei específica é inaplicável ao caso das leis sobre amianto. E isto por uma razão simples: em matéria de defesa da saúde, matéria em que os estados têm competência, não é razoável que a União exerça uma opção permissiva no lugar do estado, retirando-lhe a liberdade de atender, dentro de limites razoáveis, os interesses da comunidade. O exercício desta opção esvaziaria o compromisso assumido pelo Brasil na Convenção. (BRASIL, 2008, p. 55)

De fato, como já assinalado, em um modelo cooperativo de divisão de competências, a existência pura e simples de uma norma editada pelo âmbito federal, a título de norma geral, não pode e não deve excluir, a priori, o poder de legislar dos Estados-membros de modo suplementar, com vistas ao atendimento de suas peculiaridades regionais. A grande questão é que os motivos do voto se exauriram aqui e a complexidade da questão federativa ficou obscurecida por uma gama de fundamentos científicos que colocou em evidência as matérias de legislação concorrente de proteção à saúde e ao meio ambiente, tornando central apenas o debate da divisão de competências compartilhadas.

Aprofundar, por exemplo, a natureza da norma geral, especificando que a simples existência de norma federal não satisfaz necessariamente a exigência estabelecida como competência concorrente da União no art. 24 e, ainda, a possibilidade de que uma norma federal, mesmo considerada geral, pudesse ser suplantada por uma norma internacional teria sido um grande debate sobre a dinâmica jurídica que deve ter uma federação como abrasileira, que adotou um modelo complexo de divisão de competências articulando competências exclusivas e comuns 
em situações nem sempre fáceis de serem compreendidas dentro de uma dinâmica de convivência de três níveis de entes federados.

A força da cientificidade dos argumentos foi tão impactante que todos os votos que se seguiram protagonizaram esse debate. O ministro Eros Grau, que já havia se manifestado contrariamente ao voto do relator, propôs que o STF extrapolasse o pedido feito na inicial e declarasse inconstitucional a Lei federal, já que os estudos científicos não deixavam dúvidas sobre a prejudicialidade do uso do amianto:

Indago se, em hipóteses como essas, de confronto necessário entre lei estadual e lei federal, a Corte estaria presa ao pedido contido na petição que deflagra a análise da constitucionalidade de determinado tema. Eu penso, Senhor Presidente, que é imprescindível o exame da conformidade da Lei Federal com o texto da Constituição do Brasil. Eu não posso fazer de conta que essa afronta não existe. Desejo, pelo menos do meu ponto de vista afirmar essa inconstitucionalidade, que não posso, em hipótese alguma, fazer de conta que não vejo. Há estudos científicos segundo os quais o uso do amianto é prejudicial à saúde daqueles que manipulam o material. A Lei federal 9505 parece-me violar o art. 196 da Constituição do Brasil. (BRASIL, 2008, p. 61)

Na sequência, a ministra Carmen Lúcia decidiu retificar seu voto porque ao reexaminar a matéria se deu conta de que o direito à saúde é competência concorrente e comum entre os entes da federação, o que novamente colocaria em evidência apenas as questões relativas à divisão de competências compartilhadas:

Entretanto, reexaminando a matéria agora, verifiquei, conforme os princípios constitucionais, que especialmente alguns direitos, como o direito à saúde, são não apenas da competência concorrente, como realçou o Ministro Eros Grau quanto o Ministro Joaquim Barbosa, mas também de competência comum - é o art. 23, inc. II, da Constituição -, e que, portanto, no exercício dessa competência, aquela norma poderia ter sido editada. Razão pela qual, como eu disse, pedindo vênias ao Ministro Marco Aurélio, eu reajusto o meu voto para acompanhar a divergência, Presidente. (BRASIL, 2008, pp. 64-5)

Do mesmo modo, o ministro Ricardo Lewandowski também reviu sua posição e reforçou ainda mais a importância dos estudos científicos para a sua decisão:

O perigo para a saúde da população local ficou evidenciado pelos estudos que o Ministro Joaquim Barbosa apresentou e outros que já foram ventilados aqui ao longo desses debates. O fumus bonis iuris também ficou caracterizado não apenas pela legislação internacional que bane expressamente a produção de bens com essa matéria-prima, o amianto, de outro lado, também, pelos exemplos do direito comparado. Da tribuna veio a notícia de que os países que integram a União Europeia, agora, baniram esse produto de seu mercado. (BRASIL, 2008, p. 67)

O ministro Menezes de Direito decidiu acompanhar o voto do relator, tendo em vista que essa seria uma decisão em sede de medida cautelar e que seria prudente seguir os precedentes da Corte. Por outro lado, o ministro Carlos Britto manteve sua linha inicial de se opor ao voto do relator, reforçando seus argumentos com a invocação da normativa internacional como uma norma supralegal que estaria, portanto, acima da Lei federal e que referendaria a legitimidade dos 
Estados-membros de legislar sobre o assunto. O destaque, novamente, é para as matérias de saúde e meio ambiente:

[...] retomando o discurso do Ministro Joaquim Barbosa, a norma estadual, no caso, cumpre muito mais a Constituição Federal nesse plano da proteção à saúde ou de evitar riscos à saúde humana, à saúde da população em geral, dos trabalhadores em particular e do meio ambiente. A legislação estadual está muito mais próxima dos desígnios constitucionais, e, portanto, realiza melhor esse sumo princípio da eficacidade máxima da Constituição em matéria de direitos fundamentais, e muito mais próxima da OIT, também, do que a legislação federal. (BRASIL, 2008, p. 76)

A ministra Ellen Gracie reafirmou sua posição inicial de acompanhar o voto do relator e observou que o espaço de disputa sobre a questão do amianto, considerando que a Lei estadual produzida era de São Paulo, um dos Estados mais populosos e com grande representação na poder legislativo federal, poderia ter sido diretamente o Congresso Nacional no combate à defasada Lei federal: "O Estado de São Paulo tem uma aguerrida bancada parlamentar que poderia bem tentar fazer valer a sua oposição à legislação federal anterior” (BRASIL, 2008, p. 78).A ministra traz suas próprias discordâncias científicas sobre os debates levantados e ressalta, ainda, que o STF não pode exercer um papel semelhante ao de uma academia de ciência:

O legislador paulista, no caso, Senhor Presidente, excedeu autorização constitucional voltada para o preenchimento de lacunas, acaso verificadas na legislação federal. A norma paulista obstaculiza completamente a efetividade da norma federal ao impedir comercialização de produtos expressamente autorizados - o Ministro Carlos Britto acaba de nos ler - pela Lei $\mathrm{n}^{\circ} 9055$. Evidente, já vou repetir mais uma vez, que não somos academia de ciência. Portanto, não nos cabe definir a nocividade de produtos, mas o que se trata é de um produto completamente diferente daquele radicalmente proibido, inclusive na Convenção da OIT, que é o anfibólio. (BRASIL, 2008, p. 79)

Por fim, o voto do ministro Cezar Pelusoacompanhou os votos divergentes dos ministros Joaquim Barbosa e Eros Grau, demonstrando haver compreendido muito bem que o debate deixou de ser sobre repartição das competências e, em concordância com o abandono do tema federativo, reforçou os argumentos do protagonismo científico:

A mim me parece - e, nesse ponto, fiquei, realmente, impressionado com os fundamentos dos votos dos eminentes Ministros Joaquim Barbosa e Eros Grau que o problema pode ser posto em outro plano e em outro âmbito que não o de conflito de competência e, por isso, não se trata de precedente que ponha em risco a separação das competências. Parece-me que - e acompanho aqui, portanto, o raciocínio do eminente Ministro Eros Grau -, também por todas as razões já expostas e adiantadas pelo Ministro Joaquim Barbosa, e diante, até, dos termos da convenção internacional a que o Brasil aderiu, é reconhecido o perigo ou nocividade que o uso do amianto, nessa modalidade, representa para a saúde. (BRASIL, 2008, p. 139)

Com exceção desse último voto do ministro Cezar Peluso que afastou quase que por completo o debate da competência federativa, em geral, pode-se depreender que o foco do debate, sobretudo após a apresentação do voto vista do ministro Joaquim Barbosa, passou a ser a possibilidade de os Estados-membros legislarem de modo mais restritivo do que a União em matéria de proteção do meio ambiente e da saúde sem que isso significasse necessariamente uma afronta ao poder da esfera federal de estabelecer normas gerais. Ou ainda, a possibilidade de se 
questionar se a regulamentação de determinada matéria compartilhada foi de fato construída como uma norma geral que não limitaria o poder dos Estados-membros de legislar para atender às suas peculiaridades.

De fato, essas questões representamboa parte do conjunto de inovações e, ao mesmo tempodesafios do modelo cooperativo de federação, que passou a estar posto na CF de 1988 , ao lado do já consagrado modelo clássico de repartição de competências. O problema nesse caso específico do amianto, não é debater a legitimidade do poder de legislar dos Estados-membros em matéria compartilhada com a União, como é o caso da proteção ao meio ambiente e à saúde, para atender aos "interesses da comunidade" (BRASIL, 2008, p. 55), mas é ignorar todas as consequências que a mesma Lei estadual poderia ter trazido e trouxe quanto a questões básicas de transporte e comércio que só poderiam ser reguladas pela União por um motivo singelo: dizem respeito aos interesses comuns a todos os entes federativos, perpassando a todos indistintamente e, por isso, precisam ser regulados de modo uniforme e equitativo com o fim de garantir uma dinâmica minimamente ordenada e equânime entre os membros da federação.

O grande desafio que a questão do amianto trouxe ao modelo federativo brasileiro era o de justamente concatenar a prioridade de um tema como a garantia da proteção da saúde e do meio ambiente com a manutenção de uma dinâmica social, política e econômica de articulação e harmonia entre os entes da federação. Contudo, esse debate tornou-se totalmente secundarizado no julgamento do STF em prol da lógica da tecnocracia científica prolatada como figura principal no voto do ministro Joaquim Barbosa e à qual a maioria se rendeu, seja pela forma como interpretaram a Convenção 162 da OIT, seja pelo modo como ignoraram as possíveis consequências da legislação estadual em análise para o funcionamento dos interesses comuns à federação brasileira.

O resultado não poderia ter sido outro. Alguns anos mais tarde, em setembro de 2011 a Corte teve que enfrentar mais um pedido de medida cautelar em sede da ADPF $\mathrm{n}^{\circ} 234$, impetrada pela Associação Nacional do Transporte de Cargas e Logística em que muitas das ausências do debate feito na decisão sobre o pedido liminar da ADI n 3937 voltaram à tona como problemas práticos de primeira ordem para serem resolvidos. A controvérsia posta aqui é que, diante da confirmação de validade da norma estadual, os fiscais do trabalho passaram a impedir o transporte de produtos com amianto nas rodovias de São Paulo, inclusive nas federais. Considerando queo maior produtor de amianto é o Estado de Goiás, sempre que este vendia seu produto a um Estado da região sul ou até mesmo para o exterior, era imprescindível que o produto pudesse entrar no Estado para ser escoado, seja porque a malha viária nacional não oferece alternativa que não a de passar por São Paulo para chegar ao sul do país, seja porque o principal porto exportador do país está localizado na cidade de Santos, no Estado de São Paulo.

Diante do já anunciado, mas não enfrentado problema durante a votação da liminar na ADI n ${ }^{\circ}$ 3937, a Corte voltou a tratar do tema decidindo que, de fato, transporte interestadual era matéria de competência exclusiva da União e que, portanto, os produtos derivados do amianto poderiam adentrar o espaço estadual para seguirem sua destinação final. Não sem recordar sua tentativa de debater o assunto durante a ocasião da apreciação da medida cautelar da ADI $\mathrm{n}^{\circ}$ 3937, o ministro Marco Aurélio, também relator da ADPF $\mathrm{n}^{\circ}$ 234, argumentou a obviedade totalmente ignorada anteriormente:

Observem caber à União legislar privativamente sobre transporte - e, a meu ver, aí se encontra inserido o transporte de cargas perigosas, como o amianto - e sobre comércio interestadual e internacional. Reparem inexistir lei complementar delegando aos Estados a disciplina do tema, como se poderia cogitar ante a redação do parágrafo único do artigo 22 da Lei Maior. O bomsenso recomenda que as questões relacionadas ao interesse geral - isto é, nacional - sejam tratadas de maneira uniforme em todo o país. Os serviços públicos que, igualmente, funcionam em todo o território devem ficar a cargo da 
União. É com fundamento nessa ideia geral que a doutrina propõe a denominada prevalência do interesse como critério para a solução de conflitos, sugerindo seja reconhecida a competência da União quando a matéria transcender os interesses locais e regionais. A regulação do comércio interestadual é inequivocamente de alcance amplo e geral. Se cada Estado impuser restrições ao comércio, ora vedando o acesso aos próprios mercados, ora impedindo a exportação por meio das regiões de fronteiras internacionais, será o fim da Federação. Daí o constituinte ter atribuído à União tais temas. (BRASIL, 2011, p.11)

$\mathrm{O}$ voto do relator venceu por maioria, contando com a divergência dos ministros Carlos Britto, Celso de Mello e Cezar Peluso. Após a decisão sobre a liminar na ADI 3937, o relator, ministro Marco Aurélio decidiu pelo chamamento de uma audiência pública, que aconteceu em 24 de agosto de 2012 e que se configurou como um espaço de reforço do debate tecnocráticocientífico.

Em novembro de 2016 entrou na pauta do STF, a ADPF $\mathrm{n}^{\circ} 109$, de relatoria do ministro Edson Fachin, cujo objeto era a contestação da Lei municipal 13.113/01 que proibia o uso do amianto no município de São Paulo. Na mesma ocasião, entraram em pauta todas as ações ajuizadas pela Confederação Nacional dos Trabalhadores da Indústria sobre o mesmo tema, dentre elas a ADI $n^{\circ}$ 3937. Na ocasião, o ministro Dias Toffoli pediu vistas e recolocouo processo em pauta em 24 de agosto de 2017, quando se deu a decisão final, dez anos depois do início de sua tramitação no STF.

$\mathrm{O}$ voto-vista,que venceu por maioria, defendeu a improcedência do pedido feito na inicial e foi dividido em duas grandes partes. Uma primeira intitulada "Análise sob a perspectiva da competência legislativa" e a segunda, "O atual estágio do debate público e científico acerca do amianto crisotila (asbesto branco) e o processo de inconstitucionalidade do art. $2^{\circ}$ da Lei federal 9.095/1995".

Mesmo dedicando uma parte inteira para o debate da competência federativa, o ministro não enfrentou a questão das competências exclusivas da União, tampouco a relação de articulação que deveria existir entre as duas formas de repartição de competências da $\mathrm{CF} / 88$, dedicando-se exclusivamente ao debate do papel de legislar de cada ente federativo no sistema cooperativo de repartição de competências. Ainda que para a construção do raciocínio lógico desenvolvido pelo ministro bastasse oesclarecimento sobre as competências concorrentes, o argumento principal utilizado pelo ministro Marco Aurélio, relator do processo, foi o da existência de competências legislativas privativas da União sobre o tema do amianto, em especial,trânsito e transporte, jazidas e comércio interestadual.Contudo, a existência de tais argumentos não foi considerada.

O protagonismo da questão técnico-científica na definição do voto-vista foi uma constante e serviu como base principal para a resolução da incompatibilidade entre as normas estaduais e federal.O raciocínio desenvolvido pelo ministro foi o de que "a Lei $\mathrm{n}^{\circ}$ 9.055/1995 passou por um processo de inconstitucionalização, em razão da alteração no substrato fático do presente caso" (BRASIL, 2017, p. 15) e por isso, foi declarada incidentalmente inconstitucional. Como, de acordo com o $\S 3^{\circ}$ do art. 24 da CF/88, na ausência de lei federal os Estados-membros e DF têm a competência legislativa plena para legislar, as Leis estaduais debatidas, poderiam ser consideradas constitucionais diante do vácuo legislativo estabelecido pelo próprio voto quando do reconhecimento da inconstitucionalidade do art. $2^{\circ}$ da Lei federal.

$\mathrm{O}$ processo de inconstitucionalização estaria vinculado, na opinião do ministro, à segurança científica que o tema alcançou nos últimos tempos:

[...] deve-se considerar o avanço do conhecimento científico acerca dos efeitos do amianto à saúde e ao meio ambiente, havendo, quanto a esse aspecto, repitase, consenso científico dos órgãos deproteção à saúde acerca da natureza 
altamente cancerígena do referido mineral, o qual aponta para a impossibilidade de seu uso seguro(BRASIL, 2017, p. 16) (grifos no original).

O convencimento do ministro quanto aos perigos do amianto ocorreu em decorrência da audiência pública ocorrida em 2012. De acordo com Dias Toffoli,

[...]a realização da referida audiência pública elevou o debate sobre a questão no Tribunal a outro patamar. Com efeito, aabordagem do tema sob diferentes perspectivas desvelou uma novaordem de fatores a serem considerados no julgamento deste caso. Dentre eles, sobressai o fato de estarmos diante de um tema de natureza técnico-científica, cuja compreensão e tratamento jurídico-normativo dependem do estágio do desenvolvimento científico em que se encontre o observador.(BRASIL, 2017, p. 15) (grifos no original).

Ao atrelar o tratamento jurídico-normativo ao desenvolvimento científico da questão não restou mais lugar para o debate em outros termos que não os parametrizados pela ciência.Toda possibilidade de desenvolvimento de argumentos normativos acabou suplantada pela inexorabilidade científica sobre como o amianto se comporta no meio ambiente de forma maléfica, comprovado pelos índices de mortalidade que chegam a $80 \%$ em um ano após a descobertado diagnóstico de câncer (BRASIL, 2017, p. 17).

Até mesmo a Convenção da OIT no 162 de 1986, que não veda o uso do amianto, foi considerada pelo ministro à luz do avanço científico, apontandoque o comprometimento maior da Organização com a saúde do trabalhador indica que o compromisso internacional dos Estados requer "a alteração da legislação nacionalsobre a matéria com o fito de torná-la a mais protetiva possível,considerando o estágio do desenvolvimento científico sobre o tema” (BRASIL, 2017, p. 23).

Sob o ponto de vista imediato acerca do resultado prático-material da decisão, poderia se pensar, a priori, que a manutenção da constitucionalidade das leis estaduais que possibilitam maior proteção tanto ao meio ambiente quanto aos seres humanos foi um avanço no sentido da superação da tendência centralista do federalismo brasileiro. Contudo, a análise mais detida do processo nos indica que a afirmação dessa proteção com base apenas nas questões científicas e não nas questões científicas como mais um elemento a ser considerado dentro de quadro normativo da dinâmica federativa da Constituiçãonão representa necessariamente um avanço.

Ao contrário do que pode parecer, a decisão do ministro Dias Toffoli reforça a tendência centralista das decisões do STF em matéria federativa no âmbito da jurisdição constitucional (TOMIO; ROBL FILHO; KANAYAMA, 2015, pp.89-95). Isso porque o argumento sobre a manutenção da constitucionalidade das leis estaduais nada tem a ver com o reconhecimento da legitimidade legislativa dos entes subnacionais regulamentarem de forma mais protetiva as matérias concorrentes a partir de suas demandas regionais. Essa tese é afastada peremptoriamente pelo ministro que admite a possibilidade de manutenção das legislações subnacionais apenas diante da ausência de norma geral federal diante da declaraçãoincidental da inconstitucionalidade do art. $2^{\circ}$ da Lei 9.095/95:

Assim, se a lei federal admite, de modo restrito, o uso do amianto, em tese, a lei estadual ou municipal não poderia proibi-lo totalmente, pois, desse modo, atuaria de forma contrária à prescrição da norma geralfederal. Nesse caso, não temos norma suplementar, mas normacontrária/substitutiva à lei geral, em detrimento da competêncialegislativa da União.[...]No entanto, pelos fundamentos que serão expostos a seguir, entendo que o art. $2^{\circ}$ da Lei federal $n^{\circ}$ 9.055/1995 passou por um processo deinconstitucionalização e, no momento atual, não mais se compatibilizacom a Constituição de 1988, razão pela qual 
os estados passaram a tercompetência legislativa plena sobre a matéria até que sobrevenhaeventual nova legislação federal, nos termos do art. $24, \S \S 3^{\circ} \mathrm{e}$ $4^{\circ}$, da CF/88 (BRASIL, 2017, p. 11) (grifos no original).

No presente caso, a inconstitucionalidade incidental da Lei federal acabou servindo como um reforço à lógica centralistadeque normas gerais jamais podem ser contrariadas por leis regionais. Seguindo esse raciocínio, no momento em que uma nova lei federal for aprovada, $a b$ initio, as leis estaduais serão suspensas nos termos em que contrariarem o novo tex to legal, afinal, o ministro não vê "espaço constitucional para a tese de que, em matéria de competência legislativa concorrente - inclusive em relação à proteção do consumidor, da saúde e do meio ambiente -, as normas estaduais e municipais devam prevalecer sobre a norma geral federal caso elas sejam mais protetivas e estejam em oposição à disciplina federal”.

Na prática, o não reconhecimento dessa possibilidade de que normas regionais contrariem norma nacional naquilo que diga respeito às suas peculiaridades regionalizadas gera uma hierarquização entre as normas da federação, ainda que o ministro demonstre clareza sobre as regras de convivência em um modelo cooperativo de federação:

No modelo vertical de repartição de competências (corporificada na competência concorrente), há atividade conjunta e complementar dosentes, sem implicar hierarquia entre atos normativos de cada ente federado, mas campos de atribuição distintos, predefinidos constitucionalmente. (BRASIL, 2017, p. 07) (grifos no original)

Contudo, quando o $\S 4^{\circ}$ do art. 24 da CF/88 é interpretado sem levar e consideração o principal critério que vincula a atividade legislativa na federação, que são as distintas atribuições de interesses (nacional ou regionais) a serem defendidos pelos entes federativos, o ministro hierarquiza os níveis federativos.

Sob esse ponto de vista, o voto-vista retrocede ainda mais em relação aos debates feitos na ocasião da decisão liminar, uma vez que naquele momento o foco das discussões se concentrou na dinâmica do modelo cooperativo e na compreensão de que a Lei paulista poderia contrariar a federal porque se tratava de aumentar a proteção de seus cidadãos. A crítica feita nesse artigo a essa decisão foi a de que os ministros não se dedicaram a pensar como esse quadro cooperativo, totalmente determinado à época pelo debate cientificista, poderia subsistir diante das prerrogativas privativas da União sobre o tema, gerando a posteriori a zona de tensão com a questão do comércio interestadual dirimida na ADPF nº 234.

No voto-vista no ministro Dias Toffoli, o cientificismo seguiu sendo o protagonista do fundamento da decisão possibilitando a manutenção da tendência centralista de não reconhecer a autonomia regional para legislar contrariamente à União, quando as peculiaridades regionais se impõem e seguiu ignorando os desafios de articulação entre os modelos federativos de repartição de competências exclusivas e cooperativas.

\section{CONSIDERAÇÕES FINAIS}

O caso do amianto, estudado nesse trabalho desde a perspectiva da decisão do STF na ADI $n^{\circ}$ 3937/SP, ilustra algumas questões importantes a serem refletidas sobre os desafios contemporâneos do processo de construção e garantia de um Estado de Direito que se pretende também democrático. Sistematizaremos aqui ao menos duas dessas questões.

A primeira delas diz respeito especificamente às deficiências do debate federativo no Brasil. Isso porque desde a Constituição de 1988 o Brasil adota um sistema de divisão de 
competências misto, ou seja, abarca as competências exclusivas, também conhecidas como clássicas e ao seu lado, traz a novidade da adoção das competências compartilhadas. Essa divisão, contudo, não é estanque e, muitas vezes, não é excludente. Ou seja, pode ser que um mesmo caso de conflito de competências envolva tanto questões próprias de competências exclusivas como questões de competências compartilhadas. No caso do amianto, as questões basicamente de exploração de jazidas, comércio e transporte interestadual são de competência exclusiva da União, contudo, os malefícios à saúde da utilização desse minério na construção civil e os danos ambientais por ele causados encontram-se na seara das competências compartilhadas.Como compatibilizar essas perspectivas em termos de dinâmica federativa? Muito pouco se tem feito acerca do aprofundamento desse debate e o STF, como um espaço privilegiado de apreciação de questões desse tipo não tem conseguido contribuir a contento. Ocaso do amianto foi tratado, em um primeiro momento, como se a única possibilidade de solução do conflito federativo fosse escolher entre debater as competências exclusivas, invocadas pelo relator, ministro Marco Aurélio, ou embarcar na tese do voto divergente, apresentado pelo ministro Joaquim Barbosa, que a partir da apresentação dos dados científicos, direcionou o problema para ser uma questão só de competências compartilhadas, quando o enfrentamento das duas questões importava para a manutenção do equilíbrio federativo. Inevitavelmente, as consequências dessa primeira decisão tiveram que ser revistas em nova ação apreciada pelo STF, a ADPF n ${ }^{\circ} 234$.

Em um segundo momento, quando a decisão final foi tomada a partir do voto-vista do ministro Dias Toffoli, a questão seguiu protagonizando a cientificidade da situação também se limitando ao debate das competências compartilhadas.

A segunda questão deriva da primeira e diz respeito ao modo como o debate técnicocientífico concorreu com a questão jurídica principal, ou seja, a federação, de modo que esta ficasse secundarizada. A partir de uma "escala" valorativa sobre a importância dos resultados científicos essa questão acabou por tornar-se hierarquicamente prioritária em muitos dos votos analisadosnos dois momentos, a ponto do debate federativosobre as competências exclusivas não ter sido praticamente enfrentado por nenhum ministro que aderiu ao voto divergente, na decisão da medida cautelar, ou ao voto-vista, na decisão final. Não há nenhuma dúvida sobre a importância de se debater os malefícios da utilização do amianto, tanto para a saúde humana como para o meio ambiente, afinal, essas também são questões próprias de normatização jurídica.

O desafio, nesse caso, é perceber que, de fato, como destacou Benoit Frydman em seu livro sobre O fim do Estado de Direito, os modos de normatização técnico-científicos cada vez mais perdem seu caráter subsidiário para tornarem-se concorrentes da normatização jurídica.A naturalização desse fenômeno se dá porque nos moldes de um padrão tecnocrático de tomada de decisões a técnica se resguarda pela sua suposta neutralidade e inevitabilidade, uma vez que seus resultados são divulgados como modos de melhoria da vida humana. Contudo, essas questões não passam de subterfúgios que ocultam as reais condições de produção dessa tecnicidade, que sempre se dá a partir de intenções daqueles que detém ouacessam esse tipo de espaço produtor de uma normatividade apenas anunciada como neutra.

Assim como as normas jurídicas estão atreladas a um resultado decisório de agentes que possuem interesses e um local de fala bem determinado no mundo, os resultados de estudos técnico-científicos que servem de base para a produção das normas técnicas também o estão. Contudo, as primeiras são respaldadas minimamente pela legitimidade da representatividade e do procedimento de decidibilidadepróprio dos Estados Democráticos de Direito, enquanto as segundas estão completamente fora desse âmbito, sendo simplesmente fruto de conveniências pontuais, privadas e até mesmo aleatórias em relação às demandas de interesse público. Negligenciar a necessidade de enfrentar as questões de legitimidade do uso da técnica ou da ciência como técnica não representa um perigo apenas aos pressupostos básicos da política, como 
demonstram os enfoques mais comuns sobre a temática até o momento, mas à própria normatividade do direito.

\section{REFERÊNCIAS}

BECK, Ulrich. La sociedad del riesgo global. Siglo Veintiuno de España: Madrid, 2002.

BOBBIO, Norberto; MATTEUCCI, Nicola; PASQUINO, Gianfranco. Dicionário de política I. Brasília: Universidade de Brasília, 1998.

FRYDMAN, Benoit. O fim do Estado de Direito: governar por standards e indicadores. Porto Alegre: Livraria do Advogado, 2016.

HABERMAS, Jürgen. Técnica e ciência como “ideologia”. Lisboa: Edições 70, 1993.

BRASIL. Instituto Nacional de Câncer (INCA). Disponível em: http://www1.inca.gov.br/conteudo_view.asp?ID=15. Acesso em: 20 de maio de 2015.

BRASIL. Supremo Tribunal Federal. Medida cautelar na Ação Direta de Inconstitucionalidade n. 3937/SP.Confederação Nacional dos Trabalhadores na Indústria e Governador do Estado de SãoPaulo e Assembleia Legislativa do Estado de São Paulo. Relator: Min. Marco Aurélio.Disponível em http://redir.stf.jus.br/paginadorpub/paginador.jsp?docTP=AC\&docID=553763Acesso em 01 junho de 2017.

BRASIL. Supremo Tribunal Federal.Medida Cautelar na Arguição de Descumprimento de Preceito Fundamental n. 234/ Distrito Federal. Associação Nacional do Transporte de Cargas e Logística. e Governador do Estado de SãoPaulo e Assembleia Legislativa do Estado de São Paulo. Relator: Min. Marco Aurélio.Disponível emhttp://redir.stf.jus.br/paginadorpub/paginador.jsp?docTP=TP\&docID=1694638 Acesso em 12 de junho de 2017.

BRASIL. Supremo Tribunal Federal. Ação Direta de Inconstitucionalidade n. 3937/SP. Votovista. Ministro Dias Toffoli. Confederação Nacional dos Trabalhadores na Indústria e Governador do Estado de SãoPaulo e Assembleia Legislativa do Estado de São Paulo. Relator: Min. Marco Aurélio.Disponível em http://www.stf.jus.br/arquivo/cms/noticiaNoticiaStf/anexo/votoDTamianto.pdf Acesso em 16 dez de 2017.

LENK, Hans. Tecnocracia e tecnologia: notas sobre uma discussão ideológica. In: Tecnocracia e Ideologia. Rio de Janeiro: Biblioteca Tempo Universitário, 1975. pp. 121-144.

MARTINS, Carlos Estevan. Tecnocracia ou tecnoassessoria? In: Revista de Administração de Empresa,v.10 n. 3,jul-set. São Paulo, 1970, p. 39-60. Disponível em:

http://www.scielo.br/scielo.php?pid=S0034-75901970000300002\&script=sci_arttext. Acesso em: 25 de novembro de 2015.

OFFE, Claus. O dilema político da tecnocracia. In: Tecnocracia e Ideologia. Rio de Janeiro: Biblioteca Tempo Universitário, 1975. pp.70-84. 
PÁDUA, João Pedro Chaves Valladares. A tecnocracia jurídica: a comunidade de intérpretes do direitoe o enfraquecimento democrático. Dissertação de Mestrado apresentada à Pontifícia Universidade Católica do Rio de Janeiro, 2008, 234 p.

PINZANE, Alessandro. Democracia versus tecnocracia: apatia e participação em sociedades complexas. In: Revista Lua Nova, n. 89, pp. 135-168, São Paulo: 2013.

ROTHEN, José Carlos. Apresentação. In: Capitalismo, tecnocracia e educação:da utopia social Saintsimoniana à economia (neo)liberal Friedmaniana.Jundiaí: Paco Editorial, 2015. pp. 7-8.

TOMIO, Fabrício Ricardo de Lima; ROBL FILHO, Ilton Norberto; KANAYAMA, Rodrigo Luis. Constitucionalismo estadual e controle abstrato e concentrado de constitucionalidade nos tribunais de justiça: efeitos das ações de inconstitucionalidade (ADI) estaduais na federação brasileira. In: Revista de Direito Brasileira, ano 5, v. 12, pp. 87-110, Florianópolis: 2015. 